\title{
Lactate dehydrogenase as a prognostic marker of renal transplant recipients with severe community-acquired pneumonia: a 10-year retrospective study
}

\author{
Ying Su${ }^{1 \#}$, Min-Jie Ju ${ }^{1 \#}$, Jie-Fei Ma ${ }^{1 \#}$, Guo-Wei $\mathrm{Tu}^{1}$, Hong-Yu $\mathrm{He}^{1}$, Zhun-Yong Gu ${ }^{1}$, Yuan-Lin Song ${ }^{2}$, \\ Jing Zhang ${ }^{2}$, Zhe Luo ${ }^{1,3}$ \\ ${ }^{1}$ Department of Critical Care Medicine, ${ }^{2}$ Department of Pulmonary Medicine, Zhongshan Hospital, Fudan University, Shanghai 200032, China; \\ ${ }^{3}$ Department of Critical Care Medicine, Xiamen Branch, Zhongshan hospital, Fudan University, Xiamen 361015, China \\ Contributions: (I) Conception and design: Y Su, MJ Ju, JF Ma, Z Luo; (II) Administrative support: MJ Ju, GW Tu, Z Luo; (III) Provision of \\ study materials or patients: Y Su, MJ Ju, Z Luo; (IV) Collection and assembly of data: HY He, ZY Gu, YL Song, J Zhang; (V) Data analysis and \\ interpretation: Y Su, MJ Ju, GW Tu, Z Luo; (VI) Manuscript writing: All authors; (VII) Final approval of manuscript: All authors. \\ \#These authors contributed equally to this work. \\ Correspondence to: Zhe Luo. Department of Critical Care Medicine, Zhongshan Hospital, Fudan University, Shanghai 200032, China; Department of \\ Critical Care Medicine, Xiamen Branch, Zhongshan hospital, Fudan University, Xiamen 361015, China. Email: luo.zhe@zs-hospital.sh.cn.
}

Background: Lactate dehydrogenase $(\mathrm{LDH})$ is an easily accessible biological marker that has been associated with several pulmonary disorders. The aim of this study was to investigate the prognostic value of serum LDH in renal transplant recipients with severe community-acquired pneumonia (CAP).

Methods: A total of 77 renal transplant recipients with severe CAP admitted to the intensive care unit (ICU) were screened for eligibility in this retrospective study. Patient characteristics and laboratory tests, such as $\mathrm{LDH}$ on day $1\left(\mathrm{LDH}_{\text {day } 1}\right)$ and day $3\left(\mathrm{LDH}_{\text {day } 3}\right)$ were recorded. Cox regression models were used to assess the performance of LDH to predict 90-day mortality.

Results: Median LDH level was higher on day 1 in 90-day nonsurvivors (440 U/L, IQR, 362-1,055 U/L) than in survivors (334 U/L, IQR, 265-432 U/L; $\mathrm{P}<0.001$ ); median LDH level on day 3 in nonsurvivors was 522.5 U/L (IQR, 457.5-1,058.5 U/L) and in survivors $290 \mathrm{U} / \mathrm{L}$ (IQR, 223-387.5 U/L; $\mathrm{P}<0.001$ ). Analysis of $\mathrm{LDH}$ kinetics from day 1 to day 3 showed an increase in nonsurvivors and a decrease in survivors. Moreover, Multivariate Cox analysis showed that $\mathrm{LDH}_{\text {day } 1}$ (increase per $100 \mathrm{U} / \mathrm{L}$ ), $\mathrm{LDH}_{\text {day } 3}$ (increase per $100 \mathrm{U} / \mathrm{L}$ ) and LDH kinetics (increase per 10\%) were independently associated with 90-day mortality.

Conclusions: Serum LDH levels and LDH kinetics early were independently associated with 90-day mortality in renal transplant recipients with severe CAP. In future, the prognostic role of LDH needs to be warranted.

Keywords: Community-acquired pneumonia (CAP); severe pneumonia; lactate dehydrogenase (LDH); renal transplantation; mortality

Submitted Jun 30, 2019. Accepted for publication Sep 26, 2019.

doi: $10.21037 /$ atm.2019.10.75

View this article at: http://dx.doi.org/10.21037/atm.2019.10.75

\section{Introduction}

Community-acquired pneumonia (CAP) is a common and potentially serious entity that is associated with considerable morbidity and mortality, particularly in immunocompromised patients (1). Kidney transplant recipients, a vital subgroup of immunocompromised patients, may face an increased risk of community-acquired infection due to the long-term use of immunosuppressive therapy $(2,3)$. Moreover, CAP is the most frequent cause of admission to ICU in kidney transplant recipients, 
accounting for $50 \%$ to $60 \%$ of such cases (4-6). Severe CAP after kidney transplant is still associated with a high mortality rate, despite interdisciplinary approaches have been implemented in our center since 2009 (7-12). Although Scoring systems, such as the Pneumonia Severity Index (PSI) and CURB-65 score (confusion, blood urea nitrogen, respiratory rate, blood pressure, and age $>65$ years), and biomarkers, such as procalcitonin (PCT), are available to assess the severity and prognosis of CAP for immunocompetent patients (13-17).

Lactate dehydrogenase (LDH) is a cytoplasmic enzyme present in all major organ systems (18). The extracellular existence of $\mathrm{LDH}$ is used to reflect cell damage or inflammation (19). Several studies have reported that elevated serum LDH levels were associated with several pulmonary disorders, such as CAP, pneumocystis jiroveci pneumonia (PJP), Mycoplasma pneumoniae pneumonia (20-26). However, the clinical value of $\mathrm{LDH}$ in renal transplant recipients with severe CAP remains unclear.

Therefore, the aim of this 10-year retrospective study was to assess the role of serum LDH levels early in ICU to predict outcome of renal transplant recipients with severe CAP.

\section{Methods}

\section{Study population}

Between January 1, 2009 and July 31, 2018, a total of 106 renal transplant recipients with dyspnea were admitted to the 10-bed mixed ICU of Zhongshan Hospital, Fudan University. CAP was defined as pneumonia acquired outside of a health care setting (27). Hospital-acquired pneumonia (HAP) was defined as pneumonia that occurred after 48 $\mathrm{h}$ or more in a healthcare setting (28). Severe pneumonia was defined according to the 2007 guidelines of the Infectious Diseases Society of America/American Thoracic Society (29). One of two major criteria (acute respiratory failure requiring intubation and mechanical ventilation and septic shock requiring vasopressor use) or at least three of nine minor criteria (respiratory rate $\geq 30$ breaths/min; $\mathrm{PaO}_{2} / \mathrm{FiO}_{2}$ ratio $\leq 250 \mathrm{mmHg}$; multilobar infltrates; confusion; blood urea nitrogen level $\geq 20 \mathrm{mg} / \mathrm{dL}$; white blood cell count $<4,000$ cells $/ \mathrm{mm}^{3}$; platelet count $<100,000$ cells $/ \mathrm{mm}^{3}$; core temperature $<36{ }^{\circ} \mathrm{C}$; and hypotension requiring aggressive fluid resuscitation) were required for ICU admission. Any patient meeting the following criteria was excluded: cardiogenic pulmonary edema; complication of other site of infection, such as the urinary tract, abdomen, and intestinal tract; aspartate transaminase or alanine transaminase concentration of $>500 \mathrm{U} / \mathrm{L}$ or bilirubin $>34 \mu \mathrm{mol} / \mathrm{L}$; do not intubate (DNI) order; readmission to ICU; and HAP.

\section{ICU management}

Treatment protocols for renal transplant recipients with severe pneumonia were based on the interdisciplinary approach as previously described (7). All patients received high-resolution computed tomography examinations before and during ICU stay. Oxygen therapy at ICU admission via a conventional face mask or noninvasive mechanical ventilation (NIV) or high-flow nasal cannula (HFNC) was administered at the discretion of the treating physicians. Patients who met the following criteria were considered for endotracheal intubation: unable to clear airway secretions; unable to protect the airway; unable to maintain a $\mathrm{PaO}_{2} /$ $\mathrm{FiO}_{2}$ ratio $>100 \mathrm{mmHg}$ or $\mathrm{PaO}_{2}<60 \mathrm{mmHg}$ despite optimal oxygen management with NIV or HFNC; artery blood gas $\mathrm{pH}$ of $<7.3$ within 4-8 h; and hemodynamic instability.

On day 1 (at ICU admission), methylprednisolone (1-2 mg/kg every $12 \mathrm{~h}$ ) was initiated followed by gradual discontinuation of all immunosuppressants. Once the methylprednisolone dose was reduced to $1.0 \mathrm{mg} / \mathrm{kg}$ body weight/day, low-dose calcineurin inhibitors were added (11). Antibiotic therapy was administrated at the discretion of the treating physicians. Usually, empirical antibiotic therapy included tigecycline, moxifloxacin, or meropenem, ganciclovir, and trimethoprim/ sulfamethoxazole. Antifungal drugs were used for suspected or confirmed fungal infections.

\section{Microbiological diagnostic approach}

Diagnostic tests to identify the cause of severe pneumonia included invasive diagnostic procedures (fiberoptic bronchoscopy with bronchoalveolar lavage), noninvasive procedures (blood, urine, and sputum cultures, as well as serum antibodies against Epstein-Barr virus, cytomegalovirus, Legionella, and Mycoplasma, as determined by polymerase chain reaction analyses of blood, serum, and nasopharyngeal aspirates), or both according to the established protocol for each situation. Besides, the 1,3- $\beta$ $\mathrm{D}$ glucan test (G test), galactomannan antigen detection (GM test) and $\mathrm{T}$ cells spot test of tuberculosis infection test (T-SPOT) were performed. Tuberculin testing was 
performed as an indirect diagnosis.

\section{Data collection}

The following information was collected: patient demographics, prior immunosuppressive regimens, clinical characteristics, including the Acute Physiology and Chronic Health Evaluation II (APACHE-II) score, PSI score, CURB-65 score, $\mathrm{PaO}_{2} / \mathrm{FiO}_{2}$ ratio, acute rejection history, vasopressor use within $24 \mathrm{~h}$ after ICU admission, renal replacement therapy, invasive mechanical ventilation (IMV), and microbiological identifications. Baseline laboratory testing of hemoglobin, platelet count, white blood count, creatinine, bilirubin, $\mathrm{N}$-terminal pro-brain natriuretic peptide, troponin T, alanine aminotransferase (ALT), aspartate aminotransferase (AST), alkaline phosphatase (ALP), $\gamma$-glutamyl transpeptidase $(\gamma-\mathrm{GT})$, fibrinogen, D-dimer, PCT, LDH on day 1 and day 3 , as well as clinical outcomes, including ICU mortality, 90-day mortality, length of ICU stay and hospital stay were also recorded. LDH change (LDHc) from day 1 to day 3 was calculated using the following formula: $\mathrm{LDHc}(\%)=\left(\mathrm{LDH}_{\mathrm{day}} 3-\right.$ $\left.\mathrm{LDH}_{\text {day } 1}\right) / \mathrm{LDH}_{\text {day } 1} \times 100 \% .90$-day mortality evaluation was performed via electronic medical system or telephone interview by a certified physician.

\section{Statistical analysis}

Patient characteristics were compared using the chi-square test or Fisher's exact test for categorical variables and the Mann-Whitney $U$ test for continuous variables. Receiver operating characteristic (ROC) curves were used to examine the performance of variables to predict mortality in the ICU. The area under the curve (AUC) and Youden's index to maximize the sum of the sensitivity and specificity were calculated from ROC curves. The optimal cut-off value was based on Youden's index. Survival curves for mortality in the ICU were plotted and compared across different LDH levels using the log rank test. We performed an analysis using Cox proportional hazards regression to evaluate prognostic values of LDH. Univariate models were fitted and those associated with the outcome with a probability (P) value of $<0.1$ were introduced into multivariable models (stepwise variable-selection method). To account for the possible influence of LDH on 90-day mortality, multivariable models were constructed. Correlations between variables and LDH level were analyzed through Spearman correlation tests. A $\mathrm{P}$ value of $<0.05$ was considered statistically significant. All statistical analyses were performed using the SPSS software package, version 13.0 (SPSS, Inc., Chicago, IL, USA).

\section{Results}

\section{Patient characteristics}

Between January 1, 2009 and July 31, 2018, a total of 106 renal transplant recipients with dyspnea were admitted to the ICU. Of those, 29 patients were excluded, including 10 with cardiogenic pulmonary edema at ICU admission, 11 with multiple sites of infection, 3 who were readmitted to the ICU, 3 with HAP, one with hepatic dysfunction, and 1 with a DNI order. Finally, 77 patients with severe CAP were included for analysis (Figure 1).

The baseline characteristics are shown in Table 1. The median APACHE II score and $\mathrm{PaO}_{2} / \mathrm{FiO}_{2}$ ratio were 12 points and $197 \mathrm{mmHg}$, respectively. As compared with survivors (Table 1), nonsurvivors had higher APACHE II scores $\{17.5$ [14-26] vs. 11 [9-14], respectively, $\mathrm{P}<0.01\}$ and lower $\mathrm{PaO}_{2} / \mathrm{FiO}_{2}$ ratios $\{127$ [103-203] vs. 213 [150-274] mmHg, respectively, $\mathrm{P}<0.01\}$. The PSI and CURB-65 scores were comparable between 90-day survivors and nonsurvivors. The baseline immunosuppressive regimens included cyclosporine A (CsA), tacrolimus (TAC), mycophenolate mofetil (MMF), rapamycin (Rapa), and prednisone (Pred), which were used in different combinations; specifically, CsA + MMF + Pred in 32 patients, TAC + MMF + Pred in 39, and Rapa + MMF + Pred in 6. There was no difference in the use of the three immunosuppressive regimens between 90-day survivors and nonsurvivors (Table 1).

The laboratory tests at ICU admission are shown in Table S1. The median LDH was $360 \mathrm{U} / \mathrm{L}$ (IQR, 278-465 U/L) on day 1 and $334 \mathrm{U} / \mathrm{L}$ (IQR, 241-464.5 U/L) on day 3. Median $\mathrm{LDH}$ was higher on day 1 in 90-day nonsurvivors (440 U/L, IQR, 362-1,055 U/L) than in survivors (334 U/L, IQR, $265-$ $432 \mathrm{U} / \mathrm{L} ; \mathrm{P}<0.001)$; median $\mathrm{LDH}$ on day 3 in nonsurvivors was $522.5 \mathrm{U} / \mathrm{L}$ (IQR, 457.5-1,058.5 U/L) and in survivors 290 U/L (IQR, 223-387.5 U/L; $\mathrm{P}<0.001$ ). Analysis of LDH kinetics from day 1 to day 3 showed an increase in nonsurvivors (18.02\%, IQR, 6.59-42.14\%) and a decrease in survivors $(-10.79 \%, \mathrm{IQR},-24.36-2.83 \% ; \mathrm{P}<0.001)$. The levels of $\gamma$-GT was higher in nonsurvivors than in survivors (all $\mathrm{P}<0.05$, Table S1). Also, there were no significant differences in the median levels of hemoglobin, platelets, white blood cells, ALT, AST, ALP, serum creatinine, glomerular filtration rate, troponin $\mathrm{T}, \mathrm{N}$-terminal pro- 


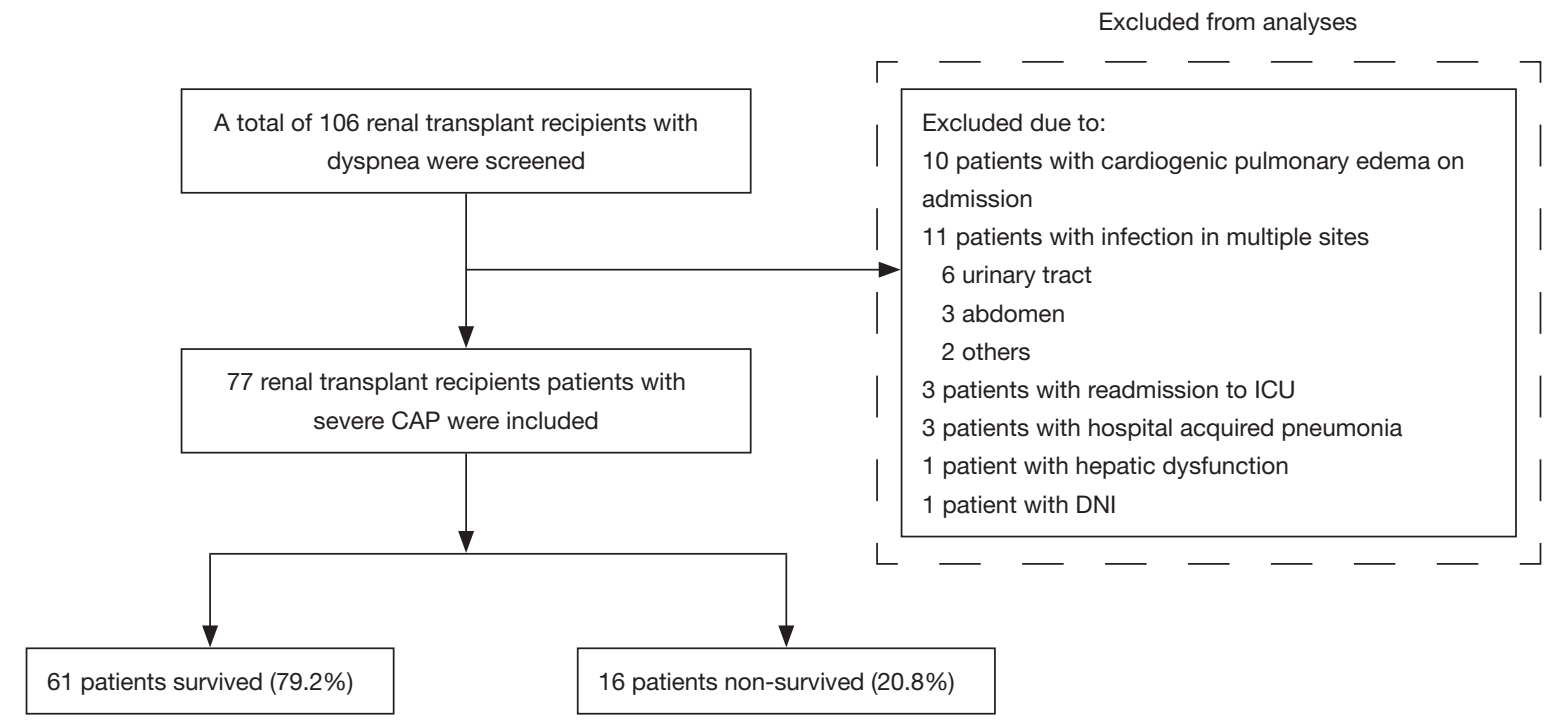

Figure 1 The enrollment of the study subjects. DNI, do not intubate; CAP, community-acquired pneumonia.

brain natriuretic peptide, fibrinogen, and D-dimer between survivors and nonsurvivors.

\section{Microbiological findings}

Forty-seven (61.0\%) patients had definitive microbiological findings based on non-invasive and/or invasive diagnostic tests (Table S2). Bacterial infection (29.9\%) was the leading cause of severe pneumonia in renal transplant recipients, followed by viral infection (23.4\%) and fungal infection (23.4\%). No pathogens were isolated in the remaining 30 (39.0\%) patients. As compared with survivors (Table S2), nonsurvivors had a higher incidence of bacterial infection ( $75.0 \%$ vs. $18.0 \%$, respectively, $\mathrm{P}<0.001)$ and lower proportion of cases with an undetermined etiology $(12.5 \%$ vs. $46.0 \%$, respectively, $\mathrm{P}=0.02)$. The incidences of viral and fungal infections were comparable between survivors and nonsurvivors.

\section{Clinical course}

Concerning the clinical course, IMV was required in 16 (20.8\%) patients. The requirement for vasopressors within $24 \mathrm{~h}$ after ICU admission, renal replacement therapy, and IMV were more common in nonsurvivors than survivors (all $\mathrm{P}<0.001$, Table S2). The ICU mortality was $18.2 \%$. The hospital and 90 -day mortality were $20.78 \%$. The median length of ICU stay and hospital stay were longer in nonsurvivors compared to survivors $\{16.5[5.5-30] v s$.
6 [3.5-10.5] days, $\mathrm{P}=0.01$ and 21 [13-29] vs. 33 [20-46], $\mathrm{P}=0.04$, respectively\}.

\section{Value of indicators to predict 90-day mortality}

ROC curves were constructed to evaluate the performance of indicators to predict 90-day mortality (Figure 2). The AUC, optimal cutoff value, sensitivity, and specificity of each indicator are shown in Table 2. The APACHE II score (AUC 0.84 \pm 0.06 ), $\mathrm{LDH}_{\text {day } 1}$ (AUC 0.78 \pm 0.06$), \mathrm{LDH}_{\text {day } 3}$ (AUC $0.93 \pm 0.03$ ) and LDH kinetics (AUC $0.85 \pm 0.06$ ) had a good power for prediction of 90 -day mortality (all $\mathrm{P}<0.001$ ). A LDH cutoff value of $\geq 375$ U/L on day 1 had a sensitivity of $75 \%$ and a specificity of $63.3 \%$. A LDH threshold of $\geq 453 \mathrm{U} / \mathrm{L}$ on day 3 had a sensitivity of $94 \%$ and a specificity of $87 \%$. LDH increase $\geq 9.2 \%$ from day 1 to day 3 had a sensitivity of $75 \%$ and a specificity of $90 \%$. PSI score had a poor power for prediction of 90 -day mortality as suggested by the AUC of $0.65 \pm 0.08(\mathrm{P}=0.07)$, which was similar to that of the CURB-65 score (AUC 0.64 $\pm 0.09, \mathrm{P}=0.09$ ).

\section{Indicators for prediction of 90-day mortality}

Survival curves for 90 day mortality are shown in Figure 3. Based on the ROC curves, the cut-off value of LDH levels on day 1 and day 3 were set at 375 and 453 U/L, respectively. Patients with higher LDH levels on day 1 ( $\geq 375 \mathrm{U} / \mathrm{L})$ and day 3 ( $\geq 453 \mathrm{U} / \mathrm{L}$ ) were at significantly higher risks of mortality (all $\mathrm{P}<0.01, \log$-rank test). 
Table 1 Clinical characteristics of patients grouped by 90-day mortality

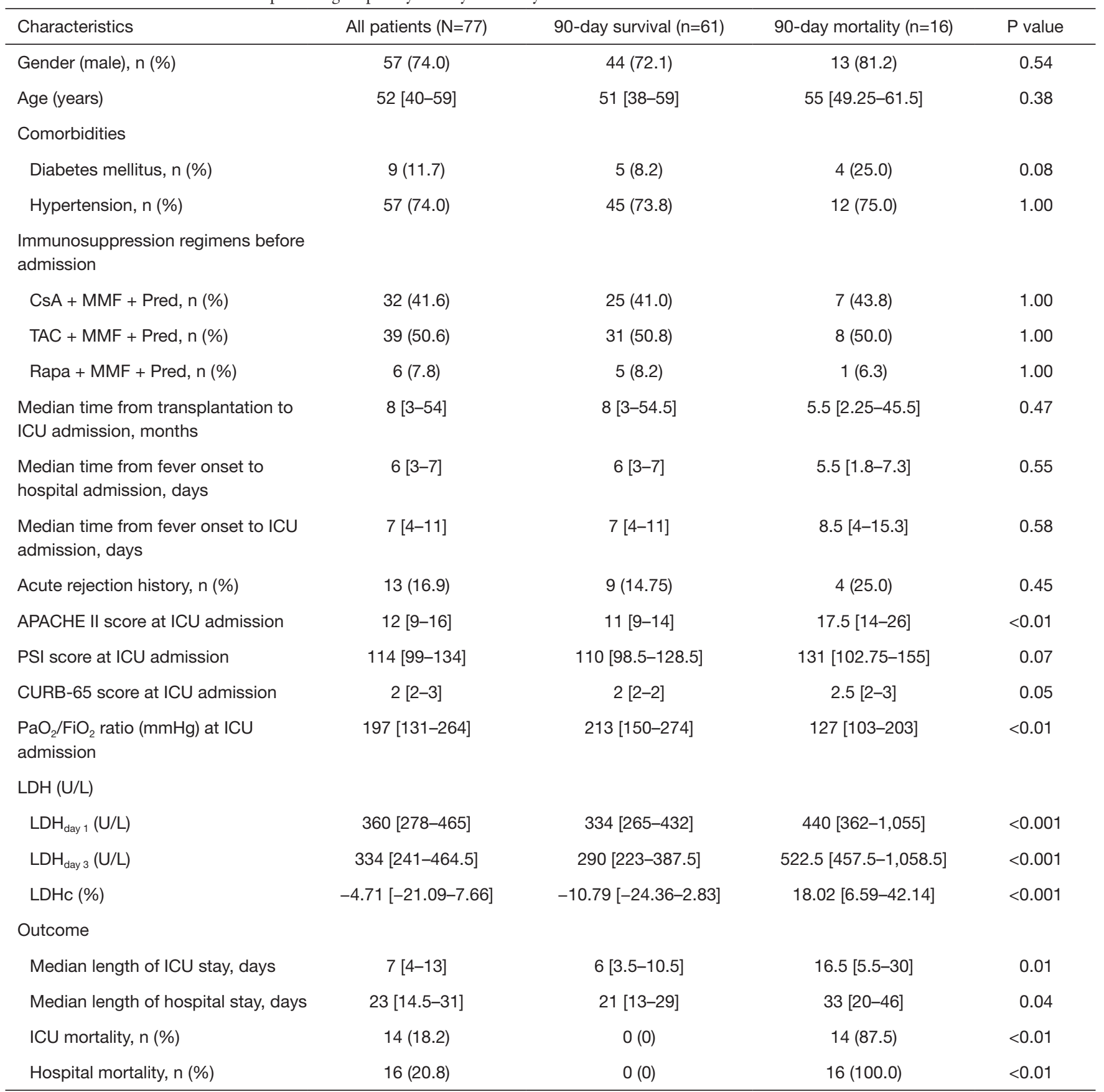

Values are median [interquartile range (IQR)] for continuous variables and percentages for categorical variables. The baseline immunosuppressive regimens included: CsA, cyclosporine A; TAC, tacrolimus; MMF, mycophenolate mofetil; Rapa, rapamycin; Pred, prednisone; APACHE-II, Acute Physiology and Chronic Health Evaluation II; PSI, Pneumonia Severity Index; ALT, alanine aminotransferase; $\mathrm{LDH}_{\text {day1 }}$, LDH level at ICU admission; $\mathrm{LDH}_{\text {day } 3}$, LDH level on day 3; LDHc, LDH change from day 1 to day 3 [calculated using the following formula: $\left.\mathrm{LDHc}(\%)=\left(\mathrm{LDH}_{\text {day } 3}-\mathrm{LDH}_{\text {day } 1}\right) / \mathrm{LDH}_{\text {day } 1} \times 100 \%\right]$. 

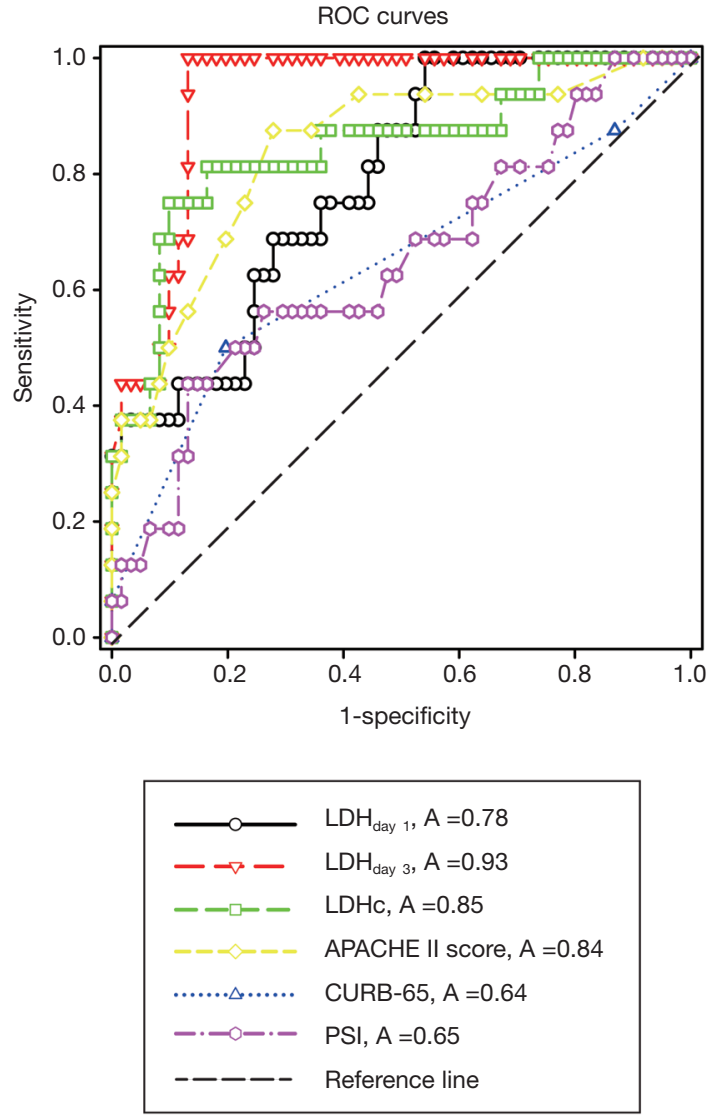

Figure 2 Receiver operating characteristic curves for APACHE II score, $\mathrm{LDH}_{\text {day } 1}, \mathrm{LDH}_{\text {day } 3}, \mathrm{LDHc}$, PSI and CURB-65 score. APACHE-II, Acute Physiology and Chronic Health Evaluation II; LDH, lactate dehydrogenase; PSI, Pneumonia Severity Index; $\mathrm{LDH}_{\text {day } 1}, \mathrm{LDH}$ level on day $1 ; \mathrm{LDH}_{\text {day } 3}, \mathrm{LDH}$ level on day 3; LDHc, LDH change from day 1 to day 3 [calculated using the following formula: $\mathrm{LDHc} \%)=\left(\mathrm{LDH}_{\text {day } 3}-\mathrm{LDH}_{\text {day } 1}\right) / \mathrm{LDH}_{\text {day } 1}$ $\times 100 \%]$.
The predictive indicators of 90-day mortality were analyzed using Cox regression and the results are listed in Table 3. In univariable analysis, APACHE II score, $\mathrm{LDH}_{\text {day } 1}$ (per $\left.100 \mathrm{U} / \mathrm{L}\right), \mathrm{LDH}_{\text {day } 3}$ (per $\left.100 \mathrm{U} / \mathrm{L}\right), \mathrm{LDH}$ kinetics (increase per $10 \%$ from day 1 to day 3 ), white blood cell count (per $10^{9} / \mathrm{L}$ ), $\mathrm{PaO}_{2} / \mathrm{FiO}_{2}$ ratio (per $100 \mathrm{mmHg}$ ) and PCT were significantly associated with 90-day mortality .

To account for the possible influence of $\mathrm{LDH}$ on 90-day mortality, multivariable models were constructed (Table 3). As the APACHE II score have repeated items of $\mathrm{PaO}_{2} / \mathrm{FiO}_{2}$ ratio and white blood cell count, APACHE II score was entered into the multivariable analysis only. In multivariable analysis, $\mathrm{LDH}_{\text {day } 1}$ (per $100 \mathrm{U} / \mathrm{L}$ ), $\mathrm{LDH}_{\text {day } 3}$ (per $100 \mathrm{U} / \mathrm{L}$ ), LDH change (per 10\%) and the APACHE II score were independently associated with 90-day mortality (Table 3).

\section{Discussion}

In the present study, we found that $\mathrm{LDH}_{\text {day } 1}$ (increase per $100 \mathrm{U} / \mathrm{L}$ ) and $\mathrm{LDH}_{\text {day } 3}$ (increase per $100 \mathrm{U} / \mathrm{L}$ ) were independently associated with 90-day mortality, and $\mathrm{LDH}_{\text {day3 }}$ had more predictive power relatively. Additional, changes of LDH early also have predictive value, which might evaluate the effectiveness of early therapy. To the best of our knowledge, this is the first study to evaluate the risk factors of severe CAP in renal transplant recipients.

$\mathrm{LDH}$ is a cytoplasmic enzyme that is widely expressed in major organs, including the brain, kidney, liver, lung, lymph nodes, myocardium, skeletal muscle, and spleen, as well as various cell types, such as erythrocytes, leucocytes, and platelets $(18,30)$. Due to the widespread distribution in the body, high LDH levels are abnormal in a majority of

Table 2 Performance of variables in predicting 90-day mortality

\begin{tabular}{|c|c|c|c|c|c|c|}
\hline Variable & AUC ROC & $95 \% \mathrm{Cl}$ & $\mathrm{P}$ & Cut-off & Sensitivity (\%) & Specificity (\%) \\
\hline $\mathrm{LDH}_{\text {day } 1}$ & $0.78 \pm 0.06$ & $0.66-0.90$ & $<0.001$ & $\geq 375$ & 75 & 63.3 \\
\hline $\mathrm{LDH}_{\text {day } 3}$ & $0.93 \pm 0.03$ & $0.88-0.98$ & $<0.001$ & $\geq 453$ & 94 & 87 \\
\hline LDHc & $0.85 \pm 0.06$ & $0.73-0.97$ & $<0.001$ & $\geq 9.2$ & 75 & 90 \\
\hline CURB-65 & $0.64 \pm 0.09$ & $0.47-0.81$ & 0.09 & $\geq 2.5$ & 50 & 80 \\
\hline
\end{tabular}

AUC ROC, area under the receiver operating characteristic curve; Cl, confidence interval; APACHE-II, Acute Physiology and Chronic Health Evaluation II; PSI, Pneumonia Severity Index; LDH day1, LDH level at ICU admission; $\mathrm{LDH}_{\text {day3 }}$, LDH level on day 3; LDHc, LDH change from day 1 to day 3 [calculated using the following formula: $\mathrm{LDHc}(\%)=\left(\mathrm{LDH}_{\text {day } 3}-\mathrm{LDH}_{\text {day } 1}\right) / \mathrm{LDH}_{\text {day } 1} \times 100 \%$ ]. 

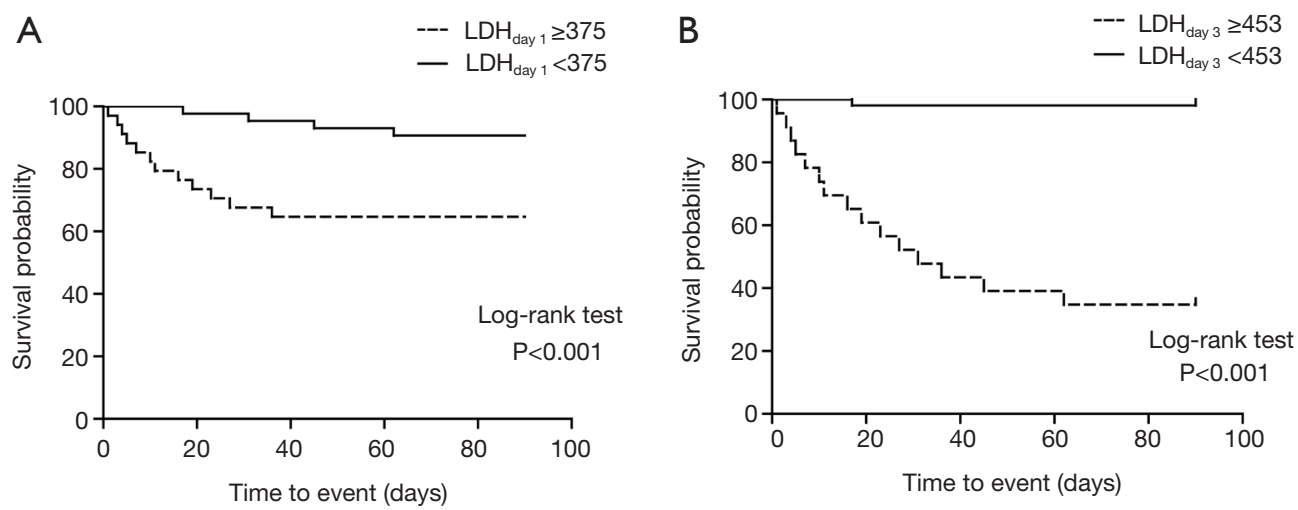

Figure 3 Kaplan-Meier curve for survival. Survival probability in patients with low and high LDH levels. A significant difference was observed with higher risk of survival events in patients with $\mathrm{LDH}_{\text {day } 1} \geq 375 \mathrm{U} / \mathrm{L}$ and $\mathrm{LDH}_{\text {day }} \geq 453 \mathrm{U} / \mathrm{L}$. Log-rank $\mathrm{P}$ value shown on graphs. $\mathrm{LDH}$, lactate dehydrogenase; $\mathrm{LDH}_{\text {day } 1}, \mathrm{LDH}$ level on day $1 ; \mathrm{LDH}_{\text {day } 3}, \mathrm{LDH}$ level on day 3 .

Table 3 Independent predictors of 90-day mortality by multivariate Cox regression analysis

\begin{tabular}{lcc}
\hline Variable & Hazard ratio $(95 \%$ Cl) & P value \\
\hline Model 1 & & $<0.001$ \\
APACHE II score at ICU admission (per point) & $1.11(1.03-1.19)$ & $<0.001$ \\
LDH $_{\text {day } 1}$ (per 100 U/L) & $1.43(1.21-1.69)$ & $<0.001$ \\
LDHc (per 10\%) & $1.31(1.13-1.52)$ & $<0.01$ \\
Model 2 & & $<0.001$ \\
APACHE II score at ICU admission (per point) & $1.11(1.03-1.19)$ & 0.04 \\
LDH & $1.36(1.17-1.57)$ \\
LDHc (per 100 U/L) $10 \%)$ & $1.16(1.00-1.34)$ & \\
\hline
\end{tabular}

Model 1 adjusted for APACHE II score at ICU admission, $\mathrm{LDH}_{\text {day } 1}$, LDHc, procalcitonin and platelet count at ICU admission. Model 2 adjusted for APACHE II score at ICU admission, $\mathrm{LDH}_{\text {day }}$, $\mathrm{LDHc}$, procalcitonin and platelet count at ICU admission (stepwise variableselection method). As the APACHE II score have repeated items of $\mathrm{PaO}_{2} / \mathrm{FiO}_{2}$ ratio and white blood cell count, APACHE II score was entered into the multivariable analysis only. APACHE-II, Acute Physiology and Chronic Health Evaluation II; LDH day1, LDH level at ICU admission (day 1); $\mathrm{LDH}_{\text {day } 3}$, $\mathrm{LDH}$ level on day 3; $\mathrm{LDHc}, \mathrm{LDH}$ change from day 1 to day 3 [calculated using the following formula: $\mathrm{LDHc}(\%)=\left(\mathrm{LDH}_{\text {day } 3}\right.$ $\left.\left.-\mathrm{LDH}_{\text {day } 1}\right) / \mathrm{LDH}_{\text {day } 1} \times 100 \%\right]$.

diseases (18), as levels are normally low in peripheral blood. Leakage of the enzyme from damaged tissues or cells can significantly increase serum LDH levels. Therefore, serum $\mathrm{LDH}$ is a sensitive, but nonspecific marker (19).

Several literatures reported that elevated serum LDH levels have been associated with severe pulmonary disorders, including CAP, PJP, mycoplasma pneumoniae pneumonia, pandemic flu, and ARDS (20-26). Cell damage, inflammation, or both may be involved in pulmonary pathogenesis in these studies (19). Elevated serum LDH levels may mainly result from damage to lung parenchymal cells or local inflammatory cells, such as alveolar macrophages and polymorphonuclear neutrophils (19). Our study revealed that renal and cardiac tests were comparable between nonsurvivors and survivors. Hence, we inferred that elevated serum LDH levels were associated with pneumonia and not attributed to renal, cardiac and hepatic dysfunction. With comprehensive suppression of the innate and adaptive immune responses by immunosuppressive agents, it is relatively difficult for renal transplant recipients to mount an effective immune response (31). This may partially explain the higher mortality of these patients with severe CAP. However, the pathophysiological mechanism underlying the association between LDH level and poorer 
outcomes of renal transplant recipients with severe CAP has not been fully elucidated.

Other clinical scores such as PSI and CURB-65 scores were not able to discriminate between nonsurvivors and survivors, which were the most frequently used scoring systems to predict CAP severity and related mortality $(15,32)$. This discrepancy can be attributed to the following reasons. First, scoring systems available to assess CAP severity and prognosis are derived from immunocompetent patients, but may not be generalizable to immunocompromised patients. Second, the PSI score usually overestimates age and can underestimate severity, particularly in patients with no comorbidity $(15,33)$.

This study had several limitations that should be addressed. First, this was a retrospective study. Second, the study was restricted by the small sample size, which might have impacted the statistic power. Third, LDH isoenzyme levels were not detected because of the restriction of local conditions, which may provide additional information for prognostic evaluation. Finally, as the cohort excluded patients with cardiogenic pulmonary edema, multiple infection sites, hepatic dysfunction, and HAP, the prognostic value of $\mathrm{LDH}$ in those patients should be applied with caution.

\section{Conclusions}

The results of this 10 -year retrospective study showed that serum LDH levels early and LDH kinetics were independently associated with 90-day mortality in renal transplant recipients with severe CAP. The prognostic role of LDH needs to be confirmed by further studies.

\section{Acknowledgments}

Funding: This article was supported by grants from the Research Funds of Zhongshan Hospital (2019ZSYXQN34, 2019ZSQN13, 2018ZSQN53 and XYYX201922) and the Research Fund of Shanghai Municipal Health Commission (2019ZB0105).

\section{Footnote}

Conflicts of Interest: The authors have no conflicts of interest to declare.

Ethical Statement: The authors are accountable for all aspects of the work in ensuring that questions related to the accuracy or integrity of any part of the work are appropriately investigated and resolved. The protocol of this retrospective study was approved by the Ethics Committee of Zhongshan Hospital, Fudan University (Shanghai, China) and conducted in accordance with the tenets of the Declaration of Helsinki. All laboratory indices were regularly measured for all patients in the ICU, thus the need for written informed consent was waived by the Ethics Review Board.

\section{References}

1. Azoulay E, Pickkers P, Soares M, et al. Acute hypoxemic respiratory failure in immunocompromised patients: the Efraim multinational prospective cohort study. Intensive Care Med 2017;43:1808-19.

2. Fishman JA. Infection in solid-organ transplant recipients. N Engl J Med 2007;357:2601-14.

3. Black CK, Termanini KM, Aguirre O, et al. Solid organ transplantation in the 21(st) century. Ann Transl Med 2018;6:409.

4. Canet E, Osman D, Lambert J, et al. Acute respiratory failure in kidney transplant recipients: a multicenter study. Crit Care 2011;15:R91.

5. Dizdar OS, Ersoy A, Akalin H. Pneumonia after kidney transplant: incidence, risk factors, and mortality. Exp Clin Transplant 2014;12:205-11.

6. Candan S, Pirat A, Varol G, et al. Respiratory problems in renal transplant recipients admitted to intensive care during long-term follow-up. Transplant Proc 2006;38:1354-6.

7. Tu GW, Ju MJ, Zheng YJ, et al. An interdisciplinary approach for renal transplant recipients with severe pneumonia: a single ICU experience. Intensive Care Med 2014;40:914-5.

8. Tu G, Ju M, Zheng Y, et al. Early- and late-onset severe pneumonia after renal transplantation. Int J Clin Exp Med 2015;8:1324-32.

9. Tu GW, Song JQ, Ting SK, et al. Acute quadriplegia caused by necrotizing myopathy in a renal transplant recipient with severe pneumonia: acute onset and complete recovery. Eur J Med Res 2015;20:11.

10. Tu GW, Ju MJ, Xu M, et al. Combination of caspofungin and low-dose trimethoprim/sulfamethoxazole for the treatment of severe Pneumocystis jirovecii pneumonia in renal transplant recipients. Nephrology (Carlton) 2013;18:736-42. 
11. Tu GW, Ju MJ, Han Y, et al. Moderate-dose glucocorticoids as salvage therapy for severe pneumonia in renal transplant recipients: a single-center feasibility study. Ren Fail 2014;36:202-9.

12. Tu G, He H, Yin K, et al. High-flow Nasal Cannula Versus Noninvasive Ventilation for Treatment of Acute Hypoxemic Respiratory Failure in Renal Transplant Recipients. Transplant Proc 2017;49:1325-30.

13. Aujesky D, Auble TE, Yealy DM, et al. Prospective comparison of three validated prediction rules for prognosis in community-acquired pneumonia. Am J Med 2005;118:384-92.

14. Fine MJ, Auble TE, Yealy DM, et al. A prediction rule to identify low-risk patients with community-acquired pneumonia. N Engl J Med 1997;336:243-50.

15. Feldman C. Prognostic scoring systems: which one is best? Curr Opin Infect Dis 2007;20:165-9.

16. Boussekey N, Leroy O, Alfandari S, et al. Procalcitonin kinetics in the prognosis of severe community-acquired pneumonia. Intensive Care Med 2006;32:469-72.

17. Bloos F, Marshall JC, Dellinger RP, et al. Multinational, observational study of procalcitonin in ICU patients with pneumonia requiring mechanical ventilation: a multicenter observational study. Crit Care 2011;15:R88.

18. Huijgen HJ, Sanders GT, Koster RW, et al. The clinical value of lactate dehydrogenase in serum: a quantitative review. Eur J Clin Chem Clin Biochem 1997;35:569-79.

19. Drent M, Cobben NA, Henderson RF, et al. Usefulness of lactate dehydrogenase and its isoenzymes as indicators of lung damage or inflammation. Eur Respir J 1996;9:1736-42.

20. Sun J, Su J, Xie Y, et al. Plasma IL-6/IL-10 Ratio and IL-8, LDH, and HBDH Level Predict the Severity and the Risk of Death in AIDS Patients with Pneumocystis Pneumonia. J Immunol Res 2016;2016:1583951.

21. Zhang Y, Zhou Y, Li S, et al. The Clinical Characteristics and Predictors of Refractory Mycoplasma pneumoniae Pneumonia in Children. Plos One 2016;11:e0156465.

22. Lu A, Wang C, Zhang X, et al. Lactate Dehydrogenase as a Biomarker for Prediction of Refractory Mycoplasma pneumoniae Pneumonia in Children. Respir Care 2015;60:1469-75.

23. Esteves F, Lee CH, de Sousa B, et al. (1-3)-beta-D-glucan in association with lactate dehydrogenase as biomarkers of Pneumocystis pneumonia (PcP) in $\mathrm{HIV}$-infected patients. Eur J Clin Microbiol Infect Dis 2014;33:1173-80.

24. Terpstra ML, Aman J, van Nieuw AG, et al. Plasma biomarkers for acute respiratory distress syndrome: a systematic review and meta-analysis*. Crit Care Med 2014;42:691-700.

25. Reyes S, Montull B, Martinez R, et al. Risk factors of A/ H1N1 etiology in pneumonia and its impact on mortality. Respir Med 2011;105:1404-11.

26. Ewig S, Bauer T, Hasper E, et al. Prognostic analysis and predictive rule for outcome of hospital-treated communityacquired pneumonia. Eur Respir J 1995;8:392-7.

27. Musher DM, Thorner AR. Community-acquired pneumonia. N Engl J Med 2014;371:1619-28.

28. Kalil AC, Metersky ML, Klompas M, et al. Management of Adults With Hospital-acquired and Ventilatorassociated Pneumonia: 2016 Clinical Practice Guidelines by the Infectious Diseases Society of America and the American Thoracic Society. Clin Infect Dis 2016;63:e61-111.

29. Mandell LA, Wunderink RG, Anzueto A, et al. Infectious Diseases Society of America/American Thoracic Society consensus guidelines on the management of communityacquired pneumonia in adults. Clin Infect Dis 2007;44 Suppl 2:S27-72.

30. Arulkumaran N, West S, Chan K, et al. Long-term renal function and survival of renal transplant recipients admitted to the intensive care unit. Clin Transplant 2012;26:E24-31.

31. Carbone J. The Immunology of Posttransplant CMV Infection: Potential Effect of CMV Immunoglobulins on Distinct Components of the Immune Response to CMV. Transplantation 2016;100 Suppl 3:S11-8.

32. Morley D, Torres A, Cilloniz C, et al. Predictors of treatment failure and clinical stability in patients with community acquired pneumonia. Ann Transl Med 2017;5:443.

33. Rello J, Rodriguez A, Lisboa T, et al. PIRO score for community-acquired pneumonia: a new prediction rule for assessment of severity in intensive care unit patients with community-acquired pneumonia. Crit Care Med 2009;37:456-62.

Cite this article as: $\mathrm{Su} \mathrm{Y,} \mathrm{Ju} \mathrm{MJ,} \mathrm{Ma} \mathrm{JF,} \mathrm{Tu} \mathrm{GW,} \mathrm{He} \mathrm{HY,} \mathrm{Gu}$ ZY, Song YL, Zhang J, Luo Z. Lactate dehydrogenase as a prognostic marker of renal transplant recipients with severe community-acquired pneumonia: a 10-year retrospective study. Ann Transl Med 2019;7(22):660. doi: 10.21037/atm.2019.10.75 
Supplementary

Table S1 Laboratory tests at ICU admission

\begin{tabular}{|c|c|c|c|c|}
\hline Variable & All patients $(\mathrm{N}=77)$ & 90-day survival $(\mathrm{n}=61)$ & 90-day mortality $(n=16)$ & $P$ value \\
\hline Platelet $\left(10^{9} / \mathrm{L}\right)$ & $197[148-230]$ & 198 [158-246] & $172.5[101.5-220.8]$ & 0.19 \\
\hline White blood cell count $\left(10^{9} / \mathrm{L}\right)$ & $7[5.0-10.3]$ & $6.95[4.3-10.1]$ & $8.21[5.3-13.6]$ & 0.13 \\
\hline ALT (U/L) & 21 [11-41.5] & $21[11-38.8]$ & $31.5[11.5-51]$ & 0.47 \\
\hline ALP (U/L) & 69 [54-99] & $68.5[54.5-89.5]$ & $82[51-118]$ & 0.50 \\
\hline$\gamma-\mathrm{GT}(\mathrm{U} / \mathrm{L})$ & 35 [22-61.5] & $31.5[20-50.25]$ & 67 [31-103] & 0.03 \\
\hline Total bilirubin ( $\mu \mathrm{mol} / \mathrm{L})$ & $6.5[4.9-9.17]$ & $6.5[4.9-9.2]$ & $6.35[4.7-11.3]$ & 0.96 \\
\hline Troponin T (ng/mL) & 0.024 [0.0125-0.083] & $0.02[0.01-0.08]$ & $0.03[0.02-0.12]$ & 0.40 \\
\hline Procalcitonin (ng/mL) & $0.16[0.07-0.45]$ & $0.16[0.08-0.35]$ & $0.11[0.07-0.67]$ & 0.78 \\
\hline GFR (CKD-EPI) $\left(\mathrm{mL} / \mathrm{min} / 1.73 \mathrm{~m}^{2}\right)$ & $52.0[36.7-76.7]$ & $52[37.6-76.9]$ & $45.5[16.9-74.8]$ & 0.34 \\
\hline Fibrinogen(mg/dL) & $436[344-547]$ & $436[344-517]$ & $441.5[254.5-623.8]$ & 0.80 \\
\hline D-dimer (mg/L) & $1.72[1.1-4.2]$ & $1.6[0.9-4.3]$ & $1.9[1.1-8.2]$ & 0.51 \\
\hline
\end{tabular}

ALT, alanine aminotransferase; AST, aspartate aminotransferase; ALP, alkaline phosphatase; $\gamma$-GT, $\gamma$-glutamyl transpeptidase; GFR, glomerular filtration rate.

Table S2 Clinical characteristics of patients during ICU stay

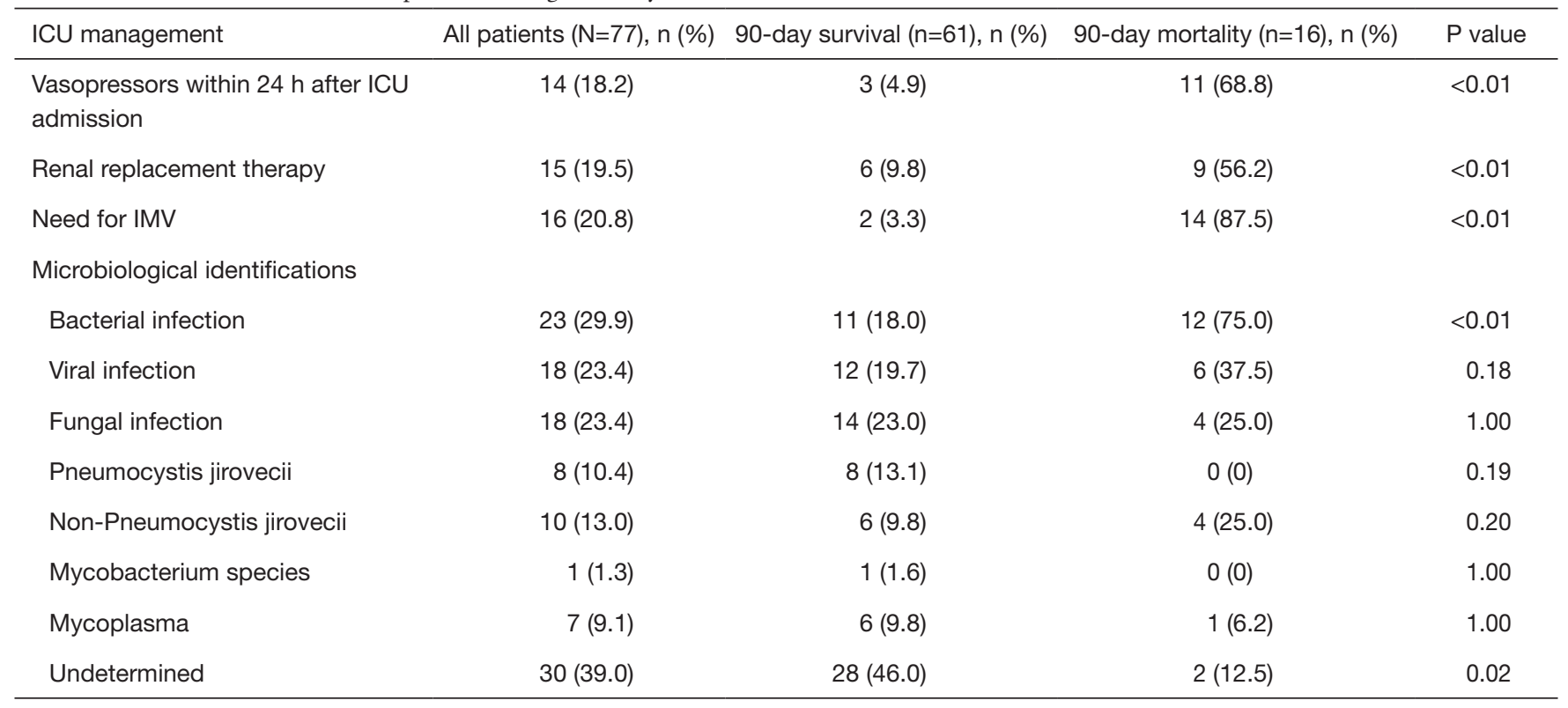

IMV, invasive mechanical ventilation. 